\title{
Jurnal

\section{HUBUNGAN BEBAN KERJA PERAWAT DAN PELAKSANAAN DOKUMENTASI ASUHAN KEPERAWATAN METODE EMR (ELECTRONIC MEDICAL RECORD) DI RUANG RAWAT INAP RS PREMIER SURABAYA}

\section{Relationships On Nurses Work And Implementation Of Nursing Documentation Method EMR (Electronic Medical Record) In Premier Hospital Surabaya}

\author{
Dwi Ernawati, Nuh Huda, Diyah Arini, Elysabeth O.P
}

Sekolah Tinggi Ilmu Kesehatan Hang Tuah Surabaya

\section{Riwayat artikel}

Diajukan: 8 Mei 2019

Diterima: 10 September 2020

\section{Penulis Korespondensi:}

- Dwi Ernawati

- STIKES Hang Tuah Surabaya

- dwiernawati@stikesha ngtuah-sby.ac.id

\section{Kata Kunci:}

Beban Kerja, Dokumentasi, EMR

\section{Abstrak}

Perawat melakukan asuhan keperawatan kepada pasien termasuk pendokumentasiannya. Dokumentasi asuhan keperawatan dengan metode EMR (Electronic Medical Record) di ruang rawat inap RS premier Surabaya bertujuan membantu pasien agar dapat terdiagnosis dengan tepat. Beberapa perawat belum melaksanakan pendokumentasian tersebut karena tindakan keperawatan yang padat di ruang rawat inap. Tujuan penelitian untuk menganalisis hubungan antara beban kerja perawat dan dokumentasi asuhan keperawatan EMR di ruang rawat inap rumah sakit premier Surabaya.

Desain Penelitian ini adalah observasional analitik dengan pendekatan cross sectional. Teknik sampling menggunakan probability sampling yaitu simple random sampling. Responden perawat rawat inap berjumlah 58 orang. Instrumen menggunakan kuesioner beban kerja dan observasi dokumentasi EMR. Data dianalisis dengan uji Spearman Rank (Rho)

Hasil penelitian menunjukkan ada hubungan antara beban kerja dan dokumentasi EMR di rawat inap berdasarkan uji korelasi Spearman Rank (Rho) menunjukan nilai p value $=0,001$.

Alokasi penggunaan waktu kerja yang lebih produktif oleh perawat diperlukan untuk mendapatkan beban kerja yang tidak berat. Penilaian kerja secara rutin juga menjadi salah satu upaya guna mendapatkan mutu pelayanan keperawatan yang lebih baik melalui pelaksanaan dokumentasi metode EMR di RS Premier Surabaya.

\section{Abstract}

Nurses perform nursing care to patients including documentation. Documentation of nursing care with the EMR (Electronic Medical Record) method in the inpatient room of Surabaya's premier hospital aims to help patients to be diagnosed correctly. Some nurses have not carried out the documentation because of the dense nursing actions in the inpatient room. The purpose of this study was to analyze the relationship between workload and documentation of EMR nursing care in the inpatient room of Surabaya's premier hospital.

The design of this study was analytic observational with cross sectional approach. The sampling technique used probability sampling, with simple random sampling. The number of inpatient nurses was 58 people. The instrument used questionnaires and observations. Data were analyzed with the Spearman Rank (Rho) test

The results showed there was a relationship between workload and EMR documentation in the hospital based on the Spearman Rank (Rho) correlation test showing a $p$ value = 0.001 .

Allocation of the use of more productive work time by nurses is needed to get a less heavy workload. Routine work assessment is also an effort to get a better quality of nursing services through implementing the EMR method documentation at Premier Surabaya Hospital. 
dari system pelayanan kesehatan sangat menentukan mutu pelayanan kesehatan. Keperawatan merupakan suatu profesi yang sangat penting dan menentukan dalam pemberian pelayanan kesehatan. Di rumah sakit keperawatan juga memegang peranan yang sangat strategis, dimana kebanyakan tenaga kesehatan adalah para perawat yang memberikan asuhan keperawatan(Swanburg, 2009). Pelayanan keperawatan yang bermutu dapat dicapai salah satunya tergantung pada seimbangnya antara jumlah tenaga dan beban kerja perawat di suatu rumah sakit. Beban kerja perawat adalah jumlah waktu yang dibutuhkan oleh perawat untuk dapat menyelesaikan seluruh tindakan keperawatan yang diwajibkan(Handayaningsih Isti, 2015). Perawat melakukan asuhan keperawatan kepada pasien termasuk pendokumentasiannya (Teytelman, 2012). Dokumentasi asuhan keperawatan dengan metode EMR (Electronic Medical Record) di ruang rawat inap RS premier Surabaya bertujuan membantu pasien agar dapat terdiagnosis dengan tepat. Beberapa perawat belum melaksanakan pendokumentasian tersebut karena tindakan keperawatan yang padat di ruang rawat inap

Beban kerja yang tidak seimbang akan mempengaruhi kerja dan layanan keperawatan sehingga layanan keperawatan akan kurang maksimal dan perawat akan mengabaikan tugasnya. Salah satu tugas yang sering diabaikan oleh perawat adalah dokumentasi keperawatan(Hidayat, 2008). Salah satu faktor yang mempengaruhi beban kerja perawat dalam melaksanakan tugas yaitu waktu kerja yang kurang memadai, seperti harus melaksanakan observasi pasien secara ketat salam jam kerja yang harus dilakukan demi kesehatan dan keselamatan pasien dan kontak langsung merawat klien secara terus menerus selama 24 jam. sehingga menyebabkan diperlukannya banyak sekali waktu untuk menyelesaikan suatu pekerjaan(Bergh, 2016)

Dokumentasi merupakan salah satu mekanisme tanggung jawab professional yang tinggi tingkatanya yang harus dilakukan oleh seorang perawat. Dalam melakukan asuhan keperawatan, perawat harus mempunyai bukti bahwa perawat telah melakukan implementasi yang berguna untuk meningkatkan status kesehatan pasien(Jeffreries, 2012). Dokumentasi asuhan keperawatan menjadi hal yang penting sebagai alat bukti tanggung jawab dan tanggung gugat dari perawat dalam menjalankan tugasnya dan sebagai alat untuk menentukan tindakan apa yang akan dilakukan oleh seorang perawat(Suarli dan Bahtiar, 2009). Perawat professional dihadapakan pada suatu tuntutan tanggung jawab yang lebih tinggi dan tanggung gugat setiap tindakan yang dilaksanakan, Artinya intervensi keperawatan yang diberikan kepada pasien harus dihindarkan terjadinya kesalah-kesalahan (negligence) dengan melakukan pendekatan proses keperawatan dan pendokumentasian yang akurat dan benar sesuai standar praktek keperawatan(Jeffreries, 2012)

Penelitian Wang et al, menggambarkan bahwa di rumah sakit Dr. Moewardi (RSDM) ada 50\% perawat mengeluh tidak puas dengan pekerjaannya(Wang, N., Hailey, 2011). Perawat menilai pekerjaan terlalu banyak, ada perawat yang memberi pelayanan pada 10-12 pasien.jumlah perawat tidak sebanding dengan jumlah pasien. Setiap jadwal dinas kerja rata-rata hanya 4 perawat, artinya 1 perawat melayani 9-11 pasien. status pasien dibangsal anggrek ternyata pada 10 status pasien dijumpai hasil pendokumentasian yang bervariasi. Pengkajian yang tidak akurat menyebabkan diagnosa keperawatan dan intervensi yang dirumuskan tidak sesuai untuk mengatasi permasalahan pasien. Kasus akibat gugatan pihak keluarga terhadap kekeliruan, ketidaklengkapan dan ketidak akuratan pencatatan sesuai kondisi pasien pernah terjadi dan mengakibatkan denda sebesar \$ 4 juta dan hukuman pidana kepada perawat(Lyer, 2015), oleh karena itu, dokumentasi yang lengkap, akurat dan serta berpedoman pada kaidah penulisan sesuai standar menjadi hal yang sangat penting 
sebagai bukti legal dan autentik di pengadilan. Dampak negatif pendokumentasian asuhan keperawatan yang tidak lengkap dapat menurunkan mutu pelayanan keperawatan karena tidak dapat menilai sejauh mana tingkat keberhasilan asuhan keperawatan yang telah diberikan (Jeffreries, 2012)

$$
\text { Pendokumentasian asuhan }
$$

keperawatan dengan metode EMR (Electronic Medical Record) di ruang rawat inap rumah sakit premier Surabaya yang lengkap diharapkan dapat membantu pasien mendapatkan penanganan secara tepat sehingga kebutuhan pasien tentang diagnosis yang ditegakkan dapat sesegera mungkin diatasi. EMR (Electronic Medical Record) adalah metode dokumentasi asuhan keperawatan oleh perawat dengan menggunakan jaringan intranet di RS Premier Surabaya. Hal ini bisa dilakukan oleh perawat dengan melakukan update ilmu pengetahuan khususnya dalam pendokumentasian asuhan keperawatan dengan metode EMR sesuai dengan perkembangan ilmu terbaru, dan mengadakan pelatihan kepada perawat yang menjalankan dokumentasi asuhan keperawatan yang baik dan benar sesuai dengan standart penilaian dari Departemen Kesehatan RI. Tujuan Umum dari penelitian ini adalah untuk menganalisis Hubungan antara beban kerja perawat dan dokumentasi asuhan keperawatan metode EMR di ruangan rawat inap Rumah Sakit Premier Surabaya.

\section{METODE}

Desain Penelitian ini adalah observasional analitik dengan pendekatan cross sectional. Teknik sampling menggunakan probability sampling yaitu simple random sampling. Responden perawat rawat inap berjumlah 58 orang. Instrumen menggunakan kuesioner dan observasi. Data dianalisis dengan uji Spearman Rank (Rho)

\section{HASIL DAN PEMBAHASAN}

Pengambilan data dilakukan pada tanggal 515 Januari 2019, dan ditetapkan 58 responden.
Penelitian berlokasi di ruang rawat inap rumah sakit premier Surabaya, meliputi ruangan rawat inap general, medical dan pediatric.

Tabel 1 Karakteristik Responden Berdasarkan Umur Perawat Ruang Rawat Inap RS Premier Surabaya.

\begin{tabular}{ccc}
\hline Umur & $\begin{array}{c}\text { Frekuensi } \\
(\mathrm{f})\end{array}$ & $\begin{array}{c}\text { Prosentase } \\
(\%)\end{array}$ \\
\hline $20-30$ & 33 & 56,9 \\
$31-40$ & 17 & 29.3 \\
$41-55$ & 8 & 13,8 \\
\hline Total & 58 & 100 \\
\hline
\end{tabular}

Sumber : Data Penelitian tahun 2019

Tabel 1 menunjukkan bahwa 56,9\% perawat Ruang Rawat Inap RS Premier Surabaya berusia 20 - 30 tahun

Tabel 2 Karakteristik Responden Berdasarkan Jenis Kelamin Perawat Ruang Rawat Inap RS Premier Surabaya.

\begin{tabular}{lcc}
\hline Jenis Kelamin & Frekuensi (f) & $\begin{array}{c}\text { Prosentase } \\
(\%)\end{array}$ \\
\hline Perempuan & 58 & 100 \\
\hline Total & 58 & 100
\end{tabular}

Sumber : Data Penelitian tahun 2019

Tabel 2 menunjukkan bahwa $100 \%$ Perawat Ruang Rawat Inap RS Premier Surabaya berjenis kelamin perempuan

Tabel 3 Karakteristik Responden Berdasarkan Pendidikan Perawat Ruang Rawat Inap RS Premier Surabaya.

\begin{tabular}{lcc}
\hline Pendidikan & Frekuensi (f) & Prosentase \\
\hline D3 & 43 & 74,1 \\
S1 & 15 & 25,9 \\
\hline Total & 58 & 100
\end{tabular}

Sumber : Data Penelitian tahun 2019

Tabel 3 menunjukkan bahwa $74,1 \%$ Perawat Ruang Rawat Inap RS Premier Surabaya mempunyai pendidikan D3 Keperawatan.

Tabel 4 Karakteristik Responden Berdasarkan Lama Kerja Perawat Ruang Rawat Inap RS Premier Surabaya. 


\begin{tabular}{lcc}
\hline Lama Kerja & Frekuensi (f) & Prosentase $(\%)$ \\
\hline$<5$ Tahun & 9 & 15,5 \\
$>5$ Tahun & 49 & 84,5 \\
\hline Total & 58 & 100 \\
\hline
\end{tabular}

Sumber : Data Penelitian tahun 2019

Tabel 4 menunjukkan bahwa $84,5 \%$ ). perawat ruang rawat inap Rumah Sakit Premier Surabaya mempunyai riwayat lama bekerja lebih dari 5 tahun

Tabel 5 Hubungan Beban Kerja dan Dokumentasi Asuhan Keperawatan metode EMR di Ruang Rawat Inap RS Premier Surabaya

\begin{tabular}{|c|c|c|c|c|c|c|c|c|}
\hline \multirow{3}{*}{$\begin{array}{l}\text { Beban } \\
\text { Kerja }\end{array}$} & \multicolumn{2}{|c|}{ Kategori } & \multicolumn{2}{|c|}{ Kategori } & \multicolumn{2}{|c|}{ Kategori } & \multicolumn{2}{|c|}{ Jumlah } \\
\hline & $\mathrm{Ba}$ & & & dang & & cang & & \\
\hline & $\sum$ & $\%$ & $\Sigma$ & $\%$ & $\sum$ & $\%$ & $\sum$ & $\%$ \\
\hline Berat & 0 & 0 & 6 & 10,3 & 6 & 10,3 & 12 & 100 \\
\hline Sedang & 21 & 36,2 & 10 & 17,2 & 3 & 5,2 & 34 & 100 \\
\hline Ringan & 10 & 17,2 & 1 & 1,7 & 1 & 1,7 & 12 & 100 \\
\hline Total & 25 & 43,1 & 23 & 39,7 & 10 & 17,2 & 58 & 100 \\
\hline
\end{tabular}

Sumber : Data Penelitian tahun 2019

Hasil Uji korelasi Spearman Rank

(Rho) menunjukan nilai $\mathrm{p}$ value $=0,001$, yang artinya bahwa ada hubungan antara Beban Kerja perawat Terhadap Dokumentasi Asuhan Keperawatan Metode EMR di Ruang Rawat Inap RS Premier Surabaya dengan

\section{PEMBAHASAN}

Perawat dengan beban ker ja berat dengan usia 41-55 berjumlah 2 perawat (3.4\%). sedangkan beban kerja ringan usia 20-30 tahun 4 perawat $(6.9 \%)$. Perawat dengan usia yang lebih tua mempunyai ritme kerja yang lebih lambat dikarenakan faktor fisik tetapi mereka lebih unggul dalam pengambilan keputusan saat ada komplain dari pasien. Gillies mendiskipsikan bahwa beban kerja adalah banyaknya pekerjaan yang harus diselesaikan sesuai job descriptionnya dan dapat memungkinkan menjadi sumber stres pekerjaan(Gillies, 2009). Rumah Sakit Premier mempunyai kualifikasi kompetensi sesuai standard mutu SDM.. Pelayanan keperawatan yang sesuai standard mutu pelayanan di ruang bangsal mengharuskan perawat dapat memberikan layanan keperawatan terbaik. Kondisi tersebut seringkali memberikan stressor bagi perawat yang baru bekerja. Perawat senior dapat lebih bijak dalam mengatasi permasalahan terkait komplain pasien di ruang rawat inap. Unsur lain yang menimbulkan beban berlebih ini adalah alokasi waktu. Pada saat atau kondisi tertentu waktu akhir dapat menjadi stimulus untuk menghasilkan prestasi kerja yang baik, namun bila tekanan waktu tersebut menimbulkan banyak kesalahan dalam pekerjaan atau menyebabkan gangguan kesehatan pada individu. Beberapa perawat tidak dapat menggunakan waktu yang tersedia dengan efektif sehingga pendokumentasian asuhan keperawatan tidak berjalan dengan baik.

Perawat dengan beban kerja berat dengan pendidikan D3 berjumlah $20 \%$ dan $10 \%$ perawat berpendidikan S1 keperawatan. Data ini dapat membuktikan bahwa pendidikan sangat berpengaruh terhadap pernyataan perawat terhadap beban kerja karena pendidikan merupakan pilar penting untuk mengatasi beban kerja berat karena dengan pendidikan yang lebih tinggi maka akan lebih tinggi pula pengetahuannya agar bekerja lebih efisien dan cepat. Hal ini sesuai dengan pernyataan dari Wang menyatakan bahwa bekerja di ruang rawat inap membutuhkan kecekatan, keterampilan, dan kesiagaan setiap saat, tanpa adanya keterampilan saat bekerja akan membuat pekerjaan menjadi berat dan membutuhkan waktu lama(Wang, N., Hailey, 2011). Perawat dengan pendidikan lebih tinggi lebih mudah dalam menggunakan manajemen waktu yang baik dalam mengelola Asuhan Keperawatan yang efektif dan efisien termasuk pendokumentasiannya

Seluruh perawat yang menyatakan memiliki beban kerja berat mempunyai riwayat lama bekerja $<5$ tahun. Nursalam menyatakan bahwa keinginan merupakan faktor psikis penyebab pekerja menyatakan 
beban kerja(Nursalam, 2011). Perawat yang memiliki minat untuk bekerja merupakan suatu bentuk motivasi diri dari perawat tersebut untuk lebih giat dalam bekerja karena jika tidak memiliki minat maka akan susah membangun motivasi diri dalam bekerja. Perawat yang sudah bekerja lama mempunyai minat dan tanggung jawab yang baik terhadap pekerjaannya sehingga berusaha untuk menyelesaikan tugasnya meskipun berat.

Tabel 5 menunjukkan bahwa beban kerja sedang dengan metode EMR kategori baik 36,2 \%, beban kerja ringan dengan dokumentasi metode EMR kategori baik $17,2 \%$, beban kerja berat dengan kelengkapan pendokumentasian dengan metode EMR kategori sedang 10,3\%. Uji Korelasi Spearman Rho menunjukan nilai $\mathrm{p}$ value $=$ 0,001 artinya secara statistik ada hubungan yang bermakna antara beban kerja dengan dokumentasi asuhan keperawatan metode EMR. Seluruh perawat yang mempunyai beban kerja berat melakukan dokumentasi dalam kategori sedang dan kurang. Rata rata perawat tersebut mempunyai pendidikan rata rata D3 dan mempunyai masa kerja $<5$ tahun. Perawat yang dimaksud adalah rata rata perawat baru bekerja yang masih berusaha menyesuaikan ritme pekerjaan di ruang rawat inap RS Premier Surabaya. Beban kerja perawat adalah jumlah pekerjaan yang harus dilakukan oleh perawat untuk dapat menyelesaikan seluruh tindakan keperawatan yang diwajibkan agar masalah kesehatan pasien teratasi(Handayaningsih Isti, 2015). Ketidakmampuan perawat baru dalam melakukan manajemen waktu menyebabkan beban kerja dipersepsikan berat sehingga tugas dokumentasi tidak terselesaikan tepat waktu.

Tabel 5 menunjukkan bahwa $83 \%$ perawat dengan beban kerja yang ringan melakukan pendokumentasian asuhan keperawatan dalam kategori sedang dan kurang, padahal dokumentasi yang lengkap, akurat dan serta berpedoman pada kaidah penulisan sesuai standar menjadi hal yang sangat penting sebagai bukti legal dan autentik di pengadilan. Dampak negatif pendokumentasian asuhan keperawatan yang tidak lengkap dapat menurunkan mutu pelayanan keperawatan karena tidak dapat menilai sejauh mana tingkat keberhasilan asuhan keperawatan yang telah diberikan(Jeffreries, 2012). $20 \%$ perawat yang pendokumentasiannya kurang terkendala dengan kemampuan dalam menggunakan teknologi EMR dikarenakan pendidikan yang masih D3 dan rata rata usianya adalah 55 tahun dan akan pensiun pada akhir tahun berjalan. Pelatihan pendokumentasian yang dilaksanakan oleh pihak RS tidak cukup membantu dalam pendokumentasian perawat tersebut. Hal ini membuktikan bahwa pendidikan dan usia sangat berpengaruh dalam kemampuan perawat untuk menggunakan media dokumentasi baru yang nyatanya bagi mereka sangat sulit dilaksanakan. Perawat berusia muda dan pendidikan tinggi nyatanya lebih mudah belajar dan mengikuti perkembangan tekhnologi utamanya sistem dokumentasi dengan metode EMR. Faktor lain yang berpengaruh adalah kemampuan kepala ruangan dalam memotivasi bawahannya agar terus semangat dalam memperbaharui pengetahuan(Nursalam, 2016)utamanya dalam mendokumentasikan asuhan keperawatan pasien di ruang rawat inap. RS Premier Surabaya.

\section{KESIMPULAN}

Beban kerja perawat berhubungan dengan dokumentasi metode EMR di ruang rawat inap RS Premier Surabaya

Alokasi penggunaan waktu kerja yang lebih produktif oleh perawat diperlukan untuk mendapatkan beban kerja yang tidak berat. Penilaian kerja secara rutin juga menjadi salah satu upaya guna mendapatkan mutu pelayanan keperawatan yang lebih baik melalui pelaksanaan dokumntasi metode EMR di RS Premier Surabaya..

\section{DAFTAR PUSTAKA}

Bergh, A. et al (2016) 'How do nurse record pedagoical activities Nurses documentasion in patients who have undergone coronary artery bypass 
surgery', Journal of Clinical Nursing, (16), pp. 1898-1907.

Gillies (2009) Manajemen Keperawatan. Jakarta: FKUI.

Handayaningsih Isti (2015) Dokumentasi Keperawatan Pedoman, Konsep dan Aplikasi. Yogyakarta.: Mitra Cendikia.

Hidayat (2008) Pengantar Konsep Dasar Keperawatan. Jakarta: Salemba Medika.

Jeffreries (2012) 'A ward-based writing coach program to improve the quality of nursing documentation', Journal Nurse Education Today, (32), pp. 647-651.

Lyer, P. . (2015) Dokumentasi Keperawatan: Suatu pendekatan proses keperawatan. Edited by 3 th. Jakarta: EGC.

Nursalam (2011) Manajemen Keperawatan: Aplikasi dalam Praktik Keperawatan Profesional. Jakarta: Salemba Medika.

Nursalam (2016) Manajemen Keperawatan. 5th edn. Edited by Lestari Peni Puji. Jakarta: Salemba Medika.

Suarli dan Bahtiar (2009) Manajemen Keperawatan dengan Pendekatan praktis. Jakarta: Erlangga.

Swanburg (2009) Pengantar Kepemimpinan dan Manajemen Keperawatan untuk Praktek Klinis. Jakarta: EGC.

Teytelman, Y. (2012) 'Effective nursing documentatio and commumication', Seminars in Oncology Nursing, 2(18), p. 12.

Wang, N., Hailey, D. (2011) 'Quality of nursing docoumentation and approaches to its evaluation: A mixed-method systematic review', Journal of Advanced Nursing, 9(67), pp. 1858-1875. 
Jurnal Ilmiah Keperawatan (Scientific Journal of Nursing), Vol 6, No 2, Tahun 2020

(Ernawati, D, et al, 2020) 